\title{
A GESTÃO ADEQUADA DOS CONFLITOS FAMILIARES A PARTIR DA MEDIAÇÃO FAMILIAR E SEUS PRESSUPOSTOS
}

\author{
Gabriela Sufiati Turra* \\ Ricardo Goretti*
}

\section{RESUMO}

Diversos são os métodos que podem ser utilizados para pacificação dos conflitos familiares, destacando-se, atualmente, a mediação familiar. Assim, questiona-se se a mediação, com base no princípio da não-violência de Jean-Marie Muller e a ética da alteridade de Luis Alberto Warat, pode promover a gestão adequada do conflito familiar, considerando suas peculiaridades, e garantir o acesso à justiça. Para responder a tal questionamento, serão analisadas as características dos conflitos familiares, os fundamentos da mediação e, por fim, se a mediação familiar representa um método adequado à gestão dos mencionados conflitos, utilizando-se, para tanto, do método hipotético-dedutivo.

PALAVRAS-CHAVES: Conflito familiar. Mediação. Não-violência. Ética da alteridade. Gestão adequada de conflitos.

\section{THE PROPER MANAGEMENT OF FAMILY CONFLICTS FROM FAMILY MEDIATION AND ITS ASSUMPTIONS}

\begin{abstract}
* Mestra em Direitos e Garantias Fundamentais pela Faculdade de Direito de Vitória - FDV. Pós-graduanda em Gestão Negociada de Conflitos pela FDV. Especialista em Direito de Família e Sucessões pela Damásio Educacional. Graduada em Direito pela FDV. Integrante do Grupo de Pesquisa "Invisibilidade Social e Energias Emancipatórias em Direitos Humanos" do PPGSS/FDV. Advogada. E-mail: gabriela_turra@hotmail.com.

* Doutor em Direitos e Garantias Fundamentais pela Faculdade de Direito de Vitória - FDV (2016). Mestre em Direitos e Garantias Fundamentais pela FDV (2008). Especialista em Resolução Alternativa de disputas pela Universidade de Buenos Aires-Argentina (2008). Especialista em Direitos e Garantias Fundamentais pela FDV (2005). Graduado em Direito pela FDV (2003). Professor do Programa de Pós-Graduação Stricto Sensu em Direitos e Garantias Fundamentais da FDV - Mestrado e Doutorado. Professor de Resolução Alternativa de Conflitos dos cursos de Graduação e Especialização em Direito da FDV. Membro do Conselho Superior da Câmara de Mediação e Arbitragem do CINDES/FINDES. Coordenador do Curso de Graduação em Direito da FDV. Consultor de órgãos públicos e instituições privadas em projetos de mediação, negociação, conciliação e arbitragem. Advogado e mediador extrajudicial. E-mail: ricardogoretti@fdv.br.
\end{abstract}


There are several methods that can be used to pacify family conflicts, highlighting, currently, family mediation. Thus, it is questioned whether mediation, based on the principle of nonviolence by Jean-Marie Muller and the ethics of otherness by Luis Alberto Warat, can promote the adequate management of family conflict, considering its peculiarities, and guarantee access to justice. To answer this question, the characteristics of family conflicts, the fundamentals of mediation and, finally, whether family mediation represents an adequate method for the management of the mentioned conflicts, using the hypothetical-deductive method, will be analyzed.

KEYWORDS: Family conflict. Mediation. No violence. Ethics of otherness. Proper conflict management.

\section{INTRODUÇÃO}

A família, desde os primórdios, representa um dos núcleos de mais importância na sociedade e é por meio dela que a maioria dos seres humanos desenvolvem suas primeiras interações uns com os outros. Assim, em razão desse seu destaque no âmbito social, inúmeros são os conflitos que podem ser instaurados a partir das relações familiares. Apesar de cada conflito possuir sua particularidade, é possível constatar que os conflitos familiares compartilham de algumas características em comum e uma delas é o caráter continuado das relações. Além disso, os conflitos familiares, por envolver assuntos frágeis e vínculos de suma importância como, por exemplo, a relação entre pais e filhos, são extremamente complexos e desafiadores.

Ocorre que, durante muitos anos, mesmo diante da complexidade dos conflitos e das relações humanas e, principalmente, dos conflitos e relações familiares, os cursos jurídicos e os profissionais do direito, fundados em uma herança histórica, não se aprofundaram no estudo do conflito e, menos ainda, nas diversas formas para sua resolução, privilegiando o processo judicial como principal meio, sem levar em consideração, na maioria das vezes, que pode o processo judicial não representar o método mais adequado a ser adotado, a depender do caso concreto. Embora a realidade acima mencionada ainda seja predominante, tem-se percebido, aos poucos, a necessidade de se adotar o método de resolução mais adequado para determinado conflito, levando em consideração todas suas peculiaridades, a fim de que, ao final, o resultado alcançado promova, de fato, a satisfação das partes envolvidas. 
Nesse sentido, a mediação tem se apresentado como um dos principais métodos alternativos de resolução de conflitos que visa, essencialmente, resgatar o protagonismo das partes, fazendo com que elas, a partir de diferenciadas técnicas utilizadas pelo mediador, possam, em conjunto, construir a solução que entendem mais adequada ao seu caso. Além de fundar-se nos princípios da flexibilidade e informalidade, a mediação pode ser utilizada, judicialmente ou extrajudicialmente, em conflitos que envolvam direitos de natureza disponível e de natureza indisponível que admitem transação. Logo, diversos são os conflitos a serem submetidos ao processo mediador, destacando, para o presente estudo, a mediação familiar, que é aquela voltada à resolução dos conflitos instaurados no âmbito familiar, já mencionados acima.

Vale dizer, ainda, que a mediação se baseia em dois importantes pressupostos, quais sejam, o princípio de não-violência desenvolvida por Jean-Marie Muller e a ética da alteridade sustentada por Luis Alberto Warat. Tais pressupostos podem ser verificados, com ainda mais evidência, nas mediações familiares, vez que os conflitos familiares, por envolverem assuntos relacionados às famílias, exigem maior atenção às questões afetas ao amor, respeito, compaixão, diálogo e empatia. Sendo assim, questiona-se: a prática da mediação, especialmente a mediação familiar, enquanto método regido pela não-violência e pautado na ética da alteridade, promove, de fato, a gestão adequada dos conflitos familiares, considerando suas peculiaridades?

A busca pela resposta para o problema acima formulado passará por três itens principais. Inicialmente, serão evidenciadas particularidades importantes dos conflitos familiares que devem ser consideradas, tanto pelos profissionais que lidam com tais conflitos quanto pelas próprias partes, a fim de que se alcance a pacificação. Ato contínuo, será examinada a mediação, destacando conceitos e princípios basilares que circundam tal método, principalmente a mediação familiar. Por fim, serão apresentados os dois pressupostos existentes na mediação, quais sejam, o princípio da não-violência de Jean Marie Muller e a ética da alteridade de Luis Alberto Warat, além da análise se a mediação familiar, ante todos seus pressupostos e objetivos, pode promover a gestão adequada dos conflitos familiares, o que se entende que sim, como será visto adiante. Ademais, a fim de responder ao 
questionamento ora formulado, será utilizado, no presente trabalho, o método hipotéticodedutivo de Karl Raymund Popper que se funda, essencialmente, na refutação, através de testes de falseamento, das soluções provisórias apresentadas. O método consiste, pois, na sequência de "problemas - teorias - críticas - novos problemas" (POPPER, 2009, p. 255). Pretende-se, com base no supracitado método, falsear os elementos da mediação familiar, considerando suas características e pressupostos, com o intuito de verificar, ao final, se tais elementos atendem às peculiaridades dos conflitos familiares, funcionando, dessa forma, como método que promove a gestão adequada de tais conflitos.

\section{OS CONFLITOS FAMILIARES E SUAS PARTICULARIDADES}

Em razão de uma herança histórica, o conflito sempre foi percebido, pela maioria da população, como prejudicial ao convívio em sociedade, o que fez com que se buscassem meios capazes de exterminá-lo o mais rápido possível, desconsiderando qualquer efeito positivo que poderia ser extraído de determinada situação, além de impossibilitar o estudo aprofundado da razão de ser do conflito e de suas eventuais funções. Essa visão negativa sobre o conflito é predominante também no âmbito do direito, o que se percebe, por exemplo, através das matrizes curriculares dos cursos jurídicos, em que há pouquíssimo ou nenhum investimento na análise do conflito, dos seus elementos estruturantes, das suas funções e das suas distintas formas de resolução, privilegiando, na maioria das vezes, a resolução dos conflitos, genericamente, por intermédio da via processual, o que pode se revelar, em alguns casos, um meio inapropriado e ineficaz. A percepção do conflito como algo desfavorável à sociedade, principalmente pelos profissionais do direito, em decorrência de sua formação jurídica, como dito, gera algumas consequências, dentre elas, o distanciamento do saber jurídico da realidade social que se funda na complexidade e a não exploração de instrumentos mais adequados à pacificação de determinado conflito, considerando todas suas particularidades. Percebe-se, pois, a necessidade de um novo olhar sobre o conflito, sendo essencial que se admita a sua imprescindibilidade para a vida em sociedade e a função por ele exercida. Nesse sentido, Luis Alberto Warat (2000, p. 31) defende que "o gesto inaugural de uma prática democrática consiste no reconhecimento da legitimidade do conflito na sociedade". Em outras palavras, o conflito deve ser reconhecido como parte legítima e indissociável da interação humana. 
Não se pretende atribuir, no presente estudo, uma carga positiva ou negativa ao conflito, mas sim entendê-lo como inerente ao convívio social, vez que o ser humano é essencialmente um ser relacional, sendo o conflito "um elemento estrutural de qualquer relação com os outros e, por conseguinte, de toda vida social" (MULLER, 2007, p. 20). Partindo desse entendimento, o conflito pode ser conceituado, de acordo as palavras de JeanMarie Muller (2006, p. 25), como: "um meio para se chegar a um acordo, um pacto que satisfaça os respectivos direitos de cada adversário e, como tal, construa relacionamentos justos e equitativos entre indivíduos e dentro de uma mesma comunidade ou, entre comunidades distintas". Seguindo a mesma perspectiva, Ricardo Goretti (2016, p. 136) afirma que os "conflitos surgem no contexto das relações humanas como eventos naturais, resultantes dos inevitáveis processos de interação humana no mundo e com o mundo". Conclui-se, portanto, que a vida em sociedade pressupõe a existência dos mais diversos conflitos, sendo algo absolutamente natural. A forma pela qual tais conflitos serão geridos é que determinará a função por eles exercida, consoante assegura Maria de Nazareth Serpa (2017, p. 21) ao dizer que "a função do conflito é determinada então pelas suas consequências que, por sua vez, são determinadas pelos mecanismo que o administra e o resolve".

Resta evidenciado, diante disso, que o conflito possui sim diversas funções que não podem ser descartadas, mas sim trabalhadas com cuidado, fazendo-se necessária a observância das peculiaridades de cada conflito para que, com base nisso, seja alcançada a forma mais adequada para sua gestão, a fim de potencializar suas funções positivas. Um dos principais tipos de conflitos são os chamados conflitos familiares, que são gerados a partir de questões que envolvem as famílias. Tais conflitos se destacam em razão de a família representar a principal maneira de relacionamento humano, cabendo mencionar que a família é considerada a base da sociedade, nos termos do artigo 226 da Constituição Federal de 1988. Os conflitos familiares, ainda, são envoltos em grande complexidade vez que dizem respeito a aspectos extremamente complicados e frágeis das relações dentro do âmbito familiar. Diante disso, ao lidar com o conflito familiar, é fundamental a conscientização de que as questões ali debatidas ultrapassam, em sua grande maioria, as discussões meramente jurídicas. Sobre isso, Filipa Alexandra Maia Magalhães (2014, p. 26) aduz: 
Torna-se fundamental olhar para o conflito familiar como algo que se desenvolve e se manifesta em torno de expectativas e interesses relevantes para o direito, mas que envolve também fortes sentimentos e emoções que não são objetivados nem valorados diretamente pelo direito. Ou seja, o conflito familiar envolve uma realidade meta-jurídica, que vai muito além do direito, que é integrada e preenchida por sentimentos da vida privada de cada uma das partes (como o ódio, a humilhação, a insegurança e a vingança), por isso, para que estes conflitos possam ser solucionados e ultrapassados, não podemos olhar para eles numa perspectiva puramente jurídica. Temos que olhar para o conflito familiar na sua totalidade e complexidade.

Tais conflitos são, inegavelmente, carregados de emoções, pois, como mencionado, estão relacionados a uma parte extremamente sensível do ser humano, qual seja, a família. Tal característica, obviamente, não se encontra apenas nos conflitos familiares, contudo, nesse tipo de conflito, ela possui espaço especial, o que torna ainda mais complexa a sua gestão, não sendo possível ignorar as emoções das partes envolvidas na busca pela pacificação de conflitos de natureza familiar. Percebe-se, então, que os conflitos familiares, em especial, carregam discussões que superam os conceitos e entendimentos jurídicos visto que tratam de temáticas sensíveis, além de se relacionarem com diversos assuntos ainda não tão aceitos no direito como, por exemplo, amor e afeto. Ao tratar dos conflitos no âmbito das famílias, Serpa (2017, p. 320) assegura:

Conflitos de família ocorrem entre pais e filhos adolescentes, ou entre cônjuges em separação, sobre guarda de filhos, ou propriedade, e são configurados por questões especialíssimas e extremamente interligadas. (...). A realidade dos conflitos familiares contém um indistinto emaranhado de conflitos legais e emocionais, e quando não são resolvidos pelos protagonistas transformam-se em disputas intermináveis nas mãos de terceiros, deixando sérias marcas na sociedade (...). Estes conflitos são tidos como mais complexos do que as próprias questões criminais. No crime, os determinantes causais são detectados pela revelação, e na família, muitos conflitos sequer deixam o campo interno de sua estrutura, para que possam ser observados.

É possível verificar, no trecho acima citado, que, nos conflitos familiares, as partes envolvidas geralmente não externam seus verdadeiros interesses que, na maioria das vezes, estão escondidos justamente atrás das emoções, o que problematiza e dificulta a satisfação das partes e o alcance do que realmente se deseja. Vale dizer, no entanto, que tal situação, na maioria dos casos, não ocorre de forma proposital, vez que as próprias partes podem não identificar seus verdadeiros interesses, o que atesta a importância de um método adequado para que o conflito seja, de fato, solucionado. Visto que a família representa um dos “institutos" essenciais ao convívio em sociedade, muitos são os conflitos que a envolvem, 
todavia, apesar de se tratar de conflitos originados de questões familiares, cada conflito possui suas próprias particularidades, sendo necessário identificar, ao lidar com determinado caso, os elementos específicos que constituem aquele quadro conflituoso. Cabe mencionar, ainda, que, embora cada conflito possua suas particularidades - verificadas a partir do caso concreto -, os conflitos familiares compartilham algumas características, cabendo destacar o caráter continuado das relações. Sobre isso, Ricardo Goretti (2019, p. 100) afirma:

Consideram-se continuadas as relações caracterizadas pela conjugação de dois fatores característicos, a saber: a) a existência de um histórico de vinculação pretérita entre as partes, anterior à manifestação do conflito; e b) a perspectiva de manutenção do vínculo pró-futuro após a superação da controvérsia. Nesses casos, além da pacificação do conflito manifesto, as partes devem desenvolver condições básicas para a preservação da convivência, prevenindo assim o surgimento de futuras disputas.

Entende-se relação continuada, portanto, como a relação que se prolonga no tempo, ou seja, a relação que já possui um histórico passado e que deverá ser mantida, por diversas razões, no futuro. Dessa forma, o vínculo que existe entre as partes é contínuo, sendo por isso que os conflitos que surgem em relações continuadas devem ser solucionados de forma efetiva e adequada. As relações conflituosas de natureza familiar, em sua grande maioria, transparecem a característica da continuidade das relações, como se constata, por exemplo, nos conflitos envolvendo o pagamento de pensão alimentícia. Percebe-se, em casos como esse, que, mesmo que o relacionamento dos pais tenha terminado, a criança - fruto dessa relação - deverá ser assistida por ambos, o que requer que eles mantenham um vínculo, mesmo após o fim do relacionamento. Este tipo de situação consiste apenas em um dos vários exemplos sobre o caráter continuado das relações dentro dos conflitos existentes no âmbito familiar, o que demonstra que tal característica é realmente comum nesse tipo de conflito, conforme mencionado.

Assim, por mais que cada caso concreto apresente suas especificidades, é possível ter uma visão geral sobre os conflitos familiares que, como dito, envolvem discussões complexas, além de relações em que há um vínculo entre as partes anterior ao conflito e, muitas vezes, é necessário que tal vínculo se mantenha após a resolução do conflito. Essas, portanto, são as características mais destacadas nos conflitos de família. Entender tais características se revela muito importante, visto que é somente a partir disso que se alcançará 
o método ou técnica mais adequada para a resolução de determinado caso concreto. É através da gestão adequada do conflito, principalmente do conflito familiar, ante as características já identificadas, que ocorrerá a sua efetiva pacificação e a satisfação dos interesses reais das partes envolvidas, sendo, nesse contexto, que a mediação se apresenta, consoante será estudado adiante.

\section{A MEDIAÇÃo COMO IMPORTANTE MÉTODO DE RESOLUÇÃo ALTERNATIVA DE CONFLITOS}

Como mencionado no item anterior, é preciso que o ensino jurídico no Brasil sofra algumas alterações. Uma delas, como já identificado, é a análise do conflito como parte da sociedade e não como algo prejudicial ou desfavorável ao desenvolvimento das relações humanas, devendo-se prestigiar, nos cursos de direito, o estudo adequado do conflito e seu papel social. Já a outra alteração é a mudança da percepção de que é apenas por meio do processo judicial que os conflitos podem ser resolvidos. Essa percepção decorre de uma cultura juridicista, tradicional e processualista que faz com os profissionais do direito, em sua maioria, não sejam receptivos aos métodos alternativos de resolução dos conflitos, o que ocasiona diversas consequências negativas no judiciário como um todo.

Com o intuito, justamente, de promover tais alterações, o Conselho Nacional de Justiça (CNJ) emitiu a Resolução no 125/2010 que dispõe sobre a Política Judiciária Nacional de tratamento adequado dos conflitos de interesses no âmbito do Poder Judiciário. Tal resolução visa divulgar e fazer com que os chamados métodos consensuais, como a mediação e a conciliação, sejam, de fato, destacados como métodos eficazes e necessários para a resolução dos variados conflitos existentes. No mesmo sentido, o Código de Processo Civil de 2015 também tem auxiliado na difusão dos métodos consensuais, ao dispor, por exemplo, em seu artigo terceiro, parágrafo terceiro, que "a conciliação, a mediação e outros métodos de solução consensual de conflitos deverão ser estimulados por juízes, advogados, defensores públicos e membros do Ministério Público, inclusive no curso do processo judicial”. Verificase, pois, que a Resolução $n^{o}$ 125/2010 emitida pelo CNJ inspirou, de certa forma, os legisladores do Código de Processo Civil, que, inclusive, estabeleceu, como norma fundamental do processo civil, o incentivo aos métodos consensuais, além dos legisladores de outras leis, como, por exemplo, a própria lei de mediação. Assim, tem-se percebido, ainda que 
aos poucos, a necessidade de utilização não só do processo judicial, mas também dos métodos alternativos, vez que a escolha do método depende das peculiaridades do conflito que se apresenta. Sobre isso, Dhieimy Quelem Waltrich (2014, p. 63) disserta:

\begin{abstract}
Por certo que os métodos alternativos de tratamento dos conflitos, em especial a mediação, se propuseram a desmistificar a compreensão do conflito com algo negativo, possibilitando sua percepção como algo próprio das relações humanas. As contradições e as inquietações fruto das diferenças entre as pessoas permitem o aprimoramento das relações. Tal como acontece nas transformações dos conflitos, as diferenças apontadas funcionam como a construção de um vínculo mais sólido.
\end{abstract}

Somente diante dessa nova perspectiva é que os conflitos serão geridos adequadamente, sendo essa gestão adequada conceituada por Ricardo Goretti (2019, p. 23) como “a prática de cognição, condução e resolução de situações conflituosas, promovida mediante o emprego do método ou técnica que melhor atenda às particularidades do caso concreto". Ante esse novo contexto, a mediação tem ganhado cada vez mais destaque no âmbito nacional, vez que, se utilizada da forma correta e sendo ela o método mais adequado para determinado caso, os resultados atingidos promovem, realmente, a resolução e pacificação do conflito instaurado. Nesse sentido, vale a análise aprofundada desse método específico de resolução de conflitos, a fim de que, ao final, seja respondido o problema apresentado no presente trabalho, qual seja, se a mediação, especialmente a mediação familiar, a partir de suas características e pressupostos, promove a gestão adequada dos conflitos familiares.

\title{
2.1 A MEDIAÇÃO COMO VIA DE ACESSO À JUSTIÇA
}

Inicialmente, pode-se pensar a mediação como uma das vias para que se efetive o acesso à justiça no Brasil. Isso porque inúmeras são as contribuições desse método para a resolução efetiva de variados conflitos, sendo somente através da real pacificação do conflito que se alcança a justiça para determinado caso. A ideia de justiça, entretanto, é completamente vaga e ambígua, o que demonstra a importância de se destacar qual a concepção adotada no presente trabalho. Nesse sentido, verifica-se que a justiça pode ser entendida "tanto como representação de uma instituição (o Judiciário), quanto como designação de um valor (o justo)" (GORETTI, 2020). Diante dessas duas concepções, a ideia valorativa de justiça é a que se adota no presente artigo, de forma que, ao se utilizar de tal 
entendimento, o acesso à justiça representa não apenas o acesso ao Judiciário, mas sim o acesso à "determinada ordem de valores e direitos fundamentais para o ser humano" (RODRIGUES, 1994, p. 28). Tal diferenciação se revela essencial visto que "compreender acesso à justiça como o equivalente ao acesso ao Judiciário, nos dias de hoje, é incorrer em equívoco de natureza metodológica” (XAVIER, 2002, p. 1). Dessa forma, faz-se necessária a conscientização de que se tratam de duas concepções diversas, consoante afirma Kazuo Watanabe (2019, p. 109-110) que diz:

O conceito de acesso à justiça passou por uma importante atualização: deixou de significar mero acesso aos órgãos judiciários para a proteção contenciosa dos direitos para constituir acesso à ordem jurídica justa, no sentido de que os cidadãos têm o direito de serem ouvidos e atendidos não somente em situação de controvérsias com outrem, como também em situação de problemas jurídicos que impeçam o pleno exercício da cidadania (...).

Partindo dessas importantes reflexões, utiliza-se a definição de acesso à justiça formulada por Ricardo Goretti (2020, no prelo):

É o direito fundamental a uma tutela ou prestação com potencial para consagração de uma ordem de valores, direitos e interesses essenciais para o indivíduo que se encontre em situação de lesão ou ameaça a direito. Um direito que pode ser consagrado mediante o percurso de diferentes vias, desde que efetivas (que pacifiquem o conflito), tempestivas (que produzam resultados em um prazo razoável) e adequadas (que atendam às particularidades do caso concreto).

O acesso à justiça, pois, é garantido a partir da utilização de vias efetivas, tempestivas e adequadas, o que demonstra que a mediação, considerando todas suas premissas, que serão analisadas detalhadamente a seguir, representa um importante método alternativo de resolução de conflitos com grande potencial de atingir a pacificação do conflito, vez que a solução alcançada não é imposta e sim construída pelos envolvidos. Assim, ao atingir a pacificação do conflito, constata-se o efetivo acesso à justiça, entendendo a expressão "justiça" em sua concepção valorativa, restando evidente como a mediação, a partir disso, pode se apresentar como uma das vias aptas a promover este importante acesso.

\subsection{MEDIAÇÃO: CONCEITO, PRINCÍPIOS E OBJETIVOS}

No que se refere à definição de mediação, Luis Alberto Warat (2004, p. 57) a conceitua como "procedimento indisciplinado de auto-ecocomposição assistida (ou 
terceirizada) dos vínculos conflitivos com o outro em suas diversas modalidades". Segundo o autor, a mediação seria um procedimento por observar rituais, técnicas e princípios específicos, todavia, tal procedimento seria indisciplinado, visto que há liberdade, mesmo diante da observância de técnicas e outros, para que o mediador e as partes possam construir a resolução para o conflito. Além disso, defende o autor que na mediação tem-se a autocomposição ecológica, pois através dela realiza-se a autonomia, além de facilitar a melhoria na qualidade de vida.

O autor Ricardo Goretti (2016, p. 162-163), por sua vez, assegura que a mediação pode ser compreendida através de três perspectivas, quais sejam, a perspectiva processual (consiste na aplicação de uma sequência lógica de atos, através de sessões conjuntas e/ou privadas conduzidas pelo mediador), a perspectiva técnica (que se relaciona com as técnicas a serem aplicadas pelo mediador durante a mediação como, por exemplo, perguntas abertas e fechadas) e, por fim, a perspectiva filosófica (através dessa perspectiva, entende-se a mediação como atitude, forma de vida). Tem-se, portanto, a partir das três perspectivas supracitadas, a seguinte definição:

Como a mediação é compreendida como processo, técnica ou filosofia, é possível defini-la como um instrumento de reflexão e assunção de responsabilidades, capaz de levar o indivíduo em conflito a virar-se para si e implicar-se na situação sobre a qual se queixa. (GORETTI, 2016, p. 163).

Com base nessa conceituação, verifica-se que a mediação se funda em alguns princípios, dentre os quais destaca-se o princípio da autoridade dos mediados, o da flexibilidade e o da informalidade. É por meio do primeiro princípio - autoridade dos mediados - que as partes são imbuídas do poder de decisão sobre o conflito, isto é, os envolvidos é que são os protagonistas da mediação, mesmo que sejam auxiliados pelo mediador. O segundo e terceiro princípios - flexibilidade e informalidade, por sua vez, "não só fazem com que cada processo mediado seja único, como também servem de justificativa para a pluralidade de modelos ou procedimentos que norteiam a prática da mediação de diferentes modos” (GORETTI, 2012, p. 155). Menciona-se, por fim, que a mediação possui alguns objetivos a serem atingidos, que são, de acordo com Ricardo Goretti (2016, p. 162163): a) a exploração aprofundada dos interesses em jogo; b) o fortalecimento do diálogo entre as partes; c) o restabelecimento da relação intersubjetiva entre os mediados; d) a 
transformação das partes; e) o empoderamento dos atores protagonistas no conflito e f) a consequente construção de uma solução acordada para o conflito. O que se constata, dos objetivos acima elencados, é que a mediação não se apresenta como um procedimento engessado e que depende da imposição de um terceiro imparcial, mas sim um método fundado na valorização do diálogo e alteridade que visa, primordialmente, o protagonismo dos envolvidos, sendo eles os responsáveis, através da exploração de seus reais desejos, pela construção da melhor solução.

Não restam dúvidas, portanto, após a análise aprofundada da mediação, como ela se revela um instrumento de suma importância para que se promova o acesso à justiça no Brasil visto que a solução alcançada pela mediação é fruto, na verdade, do diálogo dos próprios envolvidos, o que faz com que a solução, de fato, satisfaça os reais interesses em jogo, de forma a assegurar a concretização da justiça (como valor) no caso determinado. Verifica-se, ainda, por meio do princípio da flexibilidade, já mencionado, que a mediação é aplicável a conflitos de interesses de diversas naturezas. Nesse sentido, será analisado, no terceiro e último capítulo do presente artigo, se a mediação se aplica e de que forma ela se aplica aos conflitos de natureza familiar, considerando todas as características já evidenciadas.

\section{A MEdiaÇÃo FAMILIAR A PARTIR dA NÃO-VIOLÊNCIA E DA ÉTICA DA ALTERIDADE E A GESTÃO ADEQUADA DOS CONFLITOS FAMILIARES}

\subsection{A NÃO-VIOLÊNCIA E A ÉTICA DA ALTERIDADE E SUA RELAÇÃO COM A MEDIAÇÃO FAMILIAR}

Ao analisar o conceito de mediação e suas principais características, é possível verificar que o citado método se baseia em dois pressupostos essenciais, quais sejam, o princípio da não-violência de Jean-Marie Muller e a ética da alteridade de Luis Alberto Warat. Mesmo que tais pressupostos não sejam tão relacionados à mediação pela doutrina em geral, não restam dúvidas da influência que eles exercem sobre esse método e sua aplicação aos casos concretos. O princípio da não-violência, desenvolvida por Jean-Marie Muller, parte, inicialmente, do entendimento de que a sociedade é submetida a uma cultura da violência, isto é, sob a influência social que, muitas vezes, é invisível, a violência é tida como meio normal e 
que orienta o comportamento do homem. Ocorre que, segundo o autor, a violência não é um direito humano, visto que a natureza humana é predisposta tanto à violência quanto à nãoviolência, de forma que cabe ao homem decidir que parte irá cultivar. Assim, Jean-Marie Muller define que a não-violência "exige que deixemos de lado toda animosidade em relação ao nosso semelhante" (MULLER, 2006, p. 41), sendo válido destacar as reflexões realizadas pelo próprio autor quanto a tal princípio:

\begin{abstract}
A não-violência não é a conclusão de um raciocínio, não é uma dedução, mas sim uma opção da razão. O homem compreende que só é possível dar sentido à sua vida recusando-se a ceder à solicitação da violência. Dizer não à violência, afirmando que a exigência da não-violência instaura e estrutura a humanidade do homem, significa recusar a subserviência exigida pela violência e permanecer senhor de seu destino. (MULLER, 2007, p. 49).
\end{abstract}

É com base nesses fundamentos que a mediação se apresenta como um dos métodos de regulação não-violenta de conflitos visto que, como já demonstrado, o objetivo da mediação é "trazer os protagonistas da adversidade à conversação" (MULLER, 2006, 57). Em outras palavras, pretende-se, através da mediação, que as partes envolvidas no conflito consigam construir a solução adequada para sua situação, utilizando-se, para tanto, do diálogo, da empatia e da alteridade, de forma a romper com a lógica da violência. $\mathrm{O}$ autor Jean-Marie Muller, inclusive, afirma que a ideia da mediação relaciona-se com o princípio da não-violência, vez que o que se busca é "sair de um padrão competitivo de duas mãos para um processo cooperativo de três mãos" (MULLER, 2006, p. 56), ressaltando, com isso, a importância do mediador como "terceiro pacificador". Seguindo a mesma perspectiva, Ricardo Goretti (2016, p. 145) define a mediação como um instrumento a ser utilizado na superação da cultura da violência, afirmando que a mediação é o "método de ação não violenta que pode restabelecer as relações de força e garantir, por meio do diálogo transformador, a satisfação de interesses de indivíduos inseridos em relações de conflito". Não restam dúvidas, pois, da compatibilidade entre a não-violência de Jean-Marie Muller e a mediação.

É possível verificar, ainda, que um dos fundamentos da mediação é a ética da alteridade desenvolvida por Luis Alberto Warat. A mediação baseada na alteridade procura atingir muito mais do que a construção da solução para o conflito, visto que, segundo Warat (2004, p. 26), para mediar é "preciso sentir o sentimento" e, mais que isso, é preciso "sentir 
com o outro, produzir com o outro a sensibilidade de cada um" (WARAT, 2004, p. 28). Ao desenvolver sobre a ética da alteridade, Warat (2004, p. 143-144) sustenta a necessidade de "captar o outro, em seu rosto", que consiste em "ter uma mirada ética sobre o outro (...) tem a ver com uma ética da alteridade: a todos nós é necessário captar a alteridade ética do outro (...)", de forma que, através desta captação, é possível enxergar o outro "além de suas imagens, de seus simulacros, de suas representações, de seus comportamentos artificiais, fabricados para agradar ou para ter êxito". A mediação, pois, funda-se no resgate da sensibilidade e compaixão, sendo possível, diante disso, sentir o outro em sua essência e reconhecê-lo, a partir da alteridade, como pessoa e como sujeito de direitos, sendo possível destacar, inclusive, o que Warat nomeia de direitos da alteridade como, por exemplo, "direito ao amor; direito à autonomia encontro com a própria sensibilidade; (...) direito a ser escutado" (WARAT, 2010, p. 117). Sobre a mediação e alteridade, Luis Alberto Warat (2004, p. 69) destaca:

Falar da alteridade ou de outridade é dizer muito mais coisas que a referência a um procedimento cooperativo, solidário e de mútua autocomposição. Estamos falando de uma possibilidade de transformar o conflito e de nos transformarmos no conflito, tudo graças à possibilidade assistida de poder nos olhar a partir do olhar do outro. Colocar-nos no lugar do outro para entendê-lo e entendermo-nos.

Resta evidente, dessa forma, que a mediação, em geral, se apresenta como método não-violento de gestão de conflitos, fundado na alteridade. Há de se mencionar, contudo, que tais pressupostos sobressaem-se ainda mais quando vinculados a uma das "espécies" de mediação, qual seja, a mediação familiar, que é aquela voltada à resolução dos conflitos familiares. Sobre a mediação familiar, vale dizer que ela tem como objeto principal "a família em crise" (SILVA, 2004, p. 53), de forma que "a mediação ajuda os membros da família tanto nos momentos de crise quanto nos momentos de transição, melhorando a comunicação entre eles e fazendo com que os acordos sejam estabelecidos e as relações mantidas" (PARKISON, 2015, p. 39). A não-violência e a alteridade destacam-se como pontos principais na mediação familiar ao considerar, principalmente, que os conflitos familiares carregam consigo inúmeras questões camufladas e que precisam ser trabalhadas com cuidado, a fim de que a relação entre as partes envolvidas seja reconstruída, com base na sensibilidade. 
Assim, por tratar-se de um conflito familiar, que envolve uma série de pessoas e assuntos extremamente complexos e frágeis, a mediação deve ser conduzida de forma nãoviolenta, buscando o redimensionamento do conflito, a fim de que as partes compreendam a si mesmas e, a partir da alteridade, compreendam o outro. Vale ressaltar que, geralmente, como dito, as pessoas envolvidas em conflitos familiares possuem uma história anterior ao conflito, fazendo com que esses tipos de casos sejam marcados pela afetividade, por diversas memórias e eventuais rancores e feridas que não foram tratadas, intensificando a situação ora mediada. Ademais, "a emoção subjacente ao conflito tende a reduzir a capacidade de discernimento do sujeito acerca das verdadeiras intenções do Outro ao agir" (GORETTI, 2016, p. 151), o que demonstra, com ainda mais evidência, a necessidade de se tratar o conflito familiar com base na ética da alteridade. Percebe-se, diante disso, que a mediação familiar, em razão das peculiaridades dos conflitos familiares, relaciona-se, inegavelmente, de forma muito direta, com os pressupostos trabalhados, quais sejam, a não-violência de Jean-Marie Muller e a ética da alteridade de Luis Alberto Warat.

\subsection{A GESTÃO ADEQUADA DOS CONFLITOS FAMILIARES A PARTIR DA MEDIAÇÃO FAMILIAR E SEUS PRESSUPOSTOS}

Ao considerar as características gerais da mediação e, especialmente, a mediação familiar, a partir dos pressupostos da não-violência e da ética da alteridade, constata-se que esse método alternativo de resolução dos conflitos se revela como instrumento de grande potencial para promover a gestão adequada do conflito familiar, observando, obviamente, todas suas particularidades. A mediação se revela adequada, de acordo Goretti (2019, p. 100), nas seguintes situações: quando for possível o diálogo entre as partes, quando for admitida a autocomposição, quando a situação demandar a atuação de um terceiro imparcial, quando o diálogo entre os envolvidos estiver interrompido e quando o conflito for instaurado em uma relação continuada.

Das hipóteses acima, verifica-se que as quatro primeiras dependem da análise do caso concreto, todavia, a última hipótese - o conflito inserido no contexto de uma relação continuada - reforça a ideia de que a mediação pode sim ser o método mais adequado à gestão dos conflitos familiares, vez que, como visto no primeiro capítulo deste artigo, a principal 
característica desse tipo de conflito é justamente o caráter continuado das relações. Assim, nos conflitos familiares, “(...) o próprio aspecto continuativo da relação jurídica recomenda que se mantenha uma eficiente e digna comunicação entre os indivíduos e a mediação pode se tornar importante instrumento nesta polifonia dialógica" (GOLDBERG, 2018, p. 61). Percebe-se, diante disso, que um dos principais elementos da mediação se adequa a uma das características mais marcantes dos conflitos familiares, restando evidente que a adoção do método da mediação na resolução de conflitos dessa natureza pode promover sua gestão eficaz e apropriada. Outra característica da mediação que se adequa aos conflitos familiares é a busca pelo restabelecimento da relação entre as partes. Em razão do caráter continuado das relações, é preciso que a relação que foi "interrompida" pelo conflito seja restaurada, a fim de que as partes que, provavelmente, deverão manter o vínculo entre si, por algum motivo, possam conviver harmonicamente, como é o caso, por exemplo, de pessoas que se separam, mas que possuem filhos em comum e, por conta disso, embora tenham se separado como casal, necessitam manter o vínculo em prol de seus filhos. Ademais, o restabelecimento da relação, nos casos de relações continuadas, é um dos principais aspectos a serem trabalhados na mediação familiar, ao considerar que um conflito instaurado entre alguns membros de uma família pode afetar todos os outros membros e prejudicar o convívio e o relacionamento de pessoas não diretamente envolvidas, bem como a efetiva resolução do conflito.

Dessa forma, por conta dos conflitos familiares, na maioria dos casos, envolver pessoas que não necessariamente estão ligadas ao conflito, o restabelecimento da relação se revela extremamente essencial, sendo a mediação capaz de atingir esse objetivo, fazendo com que as partes compreendam a si mesmas e também ao outro e, a partir disso, possam desenvolver um diálogo. Partindo desse contexto, o fortalecimento do diálogo entre os envolvidos é outra característica essencial da mediação que se adequa aos conflitos instaurados no âmbito familiar. A partir do caráter continuado e a necessidade de restabelecimento da relação entre as partes, o fortalecimento do diálogo mostra-se indispensável para que as partes possam comunicar-se da forma devida, de maneira a se reaproximar e fortificar a relação fragilizada. Não há como buscar o restabelecimento de uma relação sem fazer com que as partes, em primeiro lugar, desenvolvam uma comunicação saudável e honesta. O diálogo é, portanto, parte necessária para que o conflito seja, de fato, 
resolvido, sendo válido ressaltar, ainda, que o diálogo se apresenta como um exercício transformador, através do qual as pessoas conseguem estabelecer verdadeiras relações.

Ante o exposto, verifica-se que a mediação pode alcançar, diante, principalmente, de seus pressupostos, o resultado mais eficaz aos conflitos familiares, vez que "na mediação, as pessoas são levadas a agir cooperativamente, diante de opções realistas e não a fazer acusações desmedidas ou pleitos baseados unicamente em seu posicionamento pessoal" (FERREIRA, 2007, p. 87). Por se revelar, diante disso, um método menos desgastante e voltado à transformação do conflito com base na alteridade, a mediação promove a gestão adequada dos conflitos familiares, atingindo um resultado realmente eficaz e satisfatório às partes envolvidas, o que pode não ocorrer, por exemplo, com a utilização do processo judicial, destacando, nesse sentido, a seguinte afirmação de Goldberg (2018, p. 62):

Uma sentença dificilmente consegue pacificar as partes nos conflitos familiares. A resposta judicial tradicional não está apta para moldar-se às causas em que estão envolvidos tantos vínculos afetivos. Há queixas, mágoas e sentimentos confusos de amor e ódio, e temores que os anseios daqueles que buscam justiça para as vezes quererem resgatar danos emocionais, do que propriamente regular reordenações econômicas.

Não se pode negar que as chances de se identificar, por meio do processo judicial, qual o real interesse das partes envolvidas no conflito familiar são mínimas, principalmente, ao considerar que as partes envolvidas nesses tipos de conflitos, geralmente, realizam pedidos que não condizem com o que realmente desejam. Em muitos casos, portanto, têm-se decisões judiciais totalmente desvinculadas do real interesse das partes, o que se torna ainda mais prejudicial à pacificação do conflito. No caso da guarda, por exemplo, “quando os pais não conseguem chegar a um acordo e recorrem ao Judiciário, algumas questões são resolvidas quase que mecanicamente, segundo uma fórmula padrão de visitação" (BRITO; CAMPOS, 2006, p. 299), mostrando-se completamente inadequada e ineficaz. Diante desse contexto, um dos principais objetivos da mediação se destaca, qual seja, a exploração aprofundada dos interesses em jogo, sendo esse elemento extremamente essencial para a resolução do conflito familiar. Como já mencionado, os conflitos familiares são carregados de subjetividade, de forma que as partes envolvidas, na maioria das vezes, trazem consigo inúmeras emoções não trabalhadas, sentimentos reprimidos, feridas abertas, o que faz com que os citados conflitos sejam verdadeiras bombas-relógio. Em razão dessa característica dos conflitos de natureza 
familiar, as partes, afundadas na emoção, perdem sua racionalidade, o que as impede, por si sós, de alcançar uma solução adequada para seu caso. Sobre isso, Goretti (2016, p. 150) afirma, inclusive, que "a emoção subjacente ao conflito tende a reduzir a capacidade de discernimento do sujeito acerca das verdadeiras intenções do Outro ao agir”. É com base nesse cenário que a mediação se apresenta, além de tudo o que já foi explanado, como um método capaz de solucionar adequadamente os conflitos familiares. Isso porque, como dito, durante a mediação, o mediador, através da adoção de diversas técnicas, explora as emoções que perpassam determinado conflito, fazendo com que tais emoções sejam adequadamente tratadas e percebidas pelas partes e não reprimidas ou sufocadas.

A maioria dessas emoções estão ligadas aos verdadeiros interesses das partes, sendo que a mediação, por promover a exploração aprofundada dos citados interesses, é capaz de trazer à tona o que se encontra escondido, dedicando-se, pois, a encontrar as raízes do conflito e resolvendo, por completo, o caso mediado, visto que, por muitas vezes, "a cognição do invisível (que não pode ser visto no comum das coisas) pode ser tão ou mais importante que a compreensão da verdade dos fatos revelados" (GORETTI, 2016, p. 168). A partir da identificação dos reais interesses e a construção, pelas próprias partes envolvidas, da solução mais adequada, através do diálogo e alteridade, a real pacificação do conflito será alcançada, ressaltando a importância, para a resolução dos conflitos familiares, do empoderamento dos atores protagonistas no conflito, que também é um dos objetivos da mediação. A mediação familiar destaca-se justamente "por significar um claro respeito pelo princípio da Mínima Intervenção Estatal que norteia o Direito de Família, preservando a autonomia, a liberdade e a dignidade dos membros envolvidos nas controvérsias familiares" (CARVALHO; SALME; ANGELUCI, 2014, p. 7).

Por fim, os conflitos familiares, como já explanado, ultrapassam, muitas vezes, questões jurídicas, o que exige a adoção de outros saberes e diversas áreas do conhecimento, a fim de que o conflito seja solucionado. Sobre isso, Nunes (2016, p. 130) assegura:

Nos processos autocompositivos é possível ir mais fundo na análise do conflito e ele precisa ser visto com toda a complexidade intrínseca à vida humana e social, com interação interdisciplinar, a exigir a interconexão de saberes e análises referentes à identificação das emoções e da razão; do passado, presente e futuro; dos sentimentos e das necessidades, entre outros. 
Diante disso, verifica-se, mais uma vez, que a mediação pode promover, em razão dos princípios da flexibilidade e informalidade, a gestão adequada do conflito familiar, vez que a mediação abre espaço para a multidisciplinaridade, o que, por sua vez, é indispensável no tratamento dos conflitos de natureza familiar. O que se constata, portanto, é que os elementos e objetivos da mediação, ressaltando a mediação familiar, se revelam aptos para atender todas as características principais dos conflitos familiares, restando evidente que a mediação familiar é sim capaz de promover a gestão adequada dos conflitos familiares, alcançando a sua pacificação e satisfazendo o real interesses das partes envolvidas.

\section{CONCLUSÃO}

Apesar da exclusividade e ineditismo de cada conflito, os conflitos familiares, em geral, apresentam características em comum, como, por exemplo, a relação continuada das partes envolvidas e a necessidade, diante disso, de se manter, na maioria das vezes, um vínculo entre as partes após o conflito, sendo esta, sem dúvidas, umas das principais características. Além disso, pode-se dizer que os conflitos familiares carregam consigo a complexidade das próprias relações das famílias, existindo, nesse tipo de conflito, discussões que ultrapassam questões jurídicas e se relacionam com assuntos que ainda não são tão aceitos no âmbito do direito, como, por exemplo, amor e afeto. Menciona-se, também, nos conflitos familiares, a inevitabilidade da construção de uma solução adequada pelos próprios envolvidos, visto que os conflitos de natureza familiar tratam de situações muito específicas e que precisam do envolvimento das partes para que se alcance o resultado que satisfaça os reais interesses. Todas as características mencionadas acima foram tratadas no início deste artigo, sendo que elas revelam a necessidade de se adotar um método que seja apropriado a todas essas peculiaridades, pois somente através de um método adequado é que se alcançará, de fato, a pacificação do conflito familiar e o real acesso à justiça, considerando a justiça como um valor.

É nesse contexto que a mediação se apresenta como um método alternativo de resolução de conflitos em ascensão e o foco não se restringe ao resultado final, mas sim na 
transformação das partes, no fortalecimento do diálogo, no empoderamento dos protagonistas do conflito e na consequente construção, em conjunto, a partir da empatia e sensibilidade, da solução que mais se adequa ao caso mediado. A mediação, conforme exposto na segunda seção deste artigo, possui os objetivos acima identificados e seus princípios próprios, dentre eles, o princípio da autoridade dos mediados, o da flexibilidade e o da informalidade. Além de tais elementos, a mediação funda-se, ainda, em dois pressupostos essenciais: o princípio de não-violência de Jean-Marie Muller e a ética da alteridade de Luis Alberto Warat.

Os citados pressupostos "baseiam" toda mediação, de forma geral, mas eles são ainda mais evidenciados na mediação familiar, que é a mediação voltada à resolução dos conflitos familiares. A evidência de tais pressupostos se dá justamente por conta das características dos conflitos de natureza familiar, já que, nesses casos, é necessário que a gestão do conflito seja não-violenta e com foco na alteridade. Ante todas essas características e pressupostos essenciais da mediação, buscou-se, na terceira seção deste estudo, verificar se todos os elementos da mediação, especialmente a mediação familiar, se mostram apropriados às características do conflito familiar. Nesse sentido, constatou-se que os mencionados elementos se adequam sim a esse tipo específico de conflito, o que funda a conclusão de que a mediação é um método capaz de promover a gestão adequada do conflito familiar e, consequentemente, sua real pacificação, que é o que se espera.

\section{REFERÊNCIAS}

ANGELUCI, Cleber Affonso; CARVALHO, Isabela Amorim de; SALME, Raiane de Lima. A família contemporânea e a mediação como relevante mecanismo de resolução dos conflitos. Revista eletrônica da Toledo Prudente, ETIC - Encontro de Iniciação Científica, v. 10, n 10, p. 1-16, 2014. Disponível em: http://intertemas.unitoledo.br/revista/index.php/ETIC/article/viewFile/4164/3923. Acesso em: 06 jul 2020.

BRITO, Enrica Gentilezza de; CAMPOS, Argene. O papel da mediação no direito de família: separação e guarda compartilhada. In: PEREIRA, Rodrigo da Cunha; PEREIRA, Tânia da Silva. A ética da convivência familiar e sua efetividade no cotidiano dos tribunais. Rio de Janeiro: Forense, 2006.

BRASIL. Constituição da República Federativa do Brasil de 1988. Brasília, DF: Presidência da República, 2016. Disponível em: http://www.planalto.gov.br/ccivil_03/Constituicao/Constituiçao.htm. Acesso em: 30 jun 2020.

BRASIL. Código de Processo Civil de 2015. Lei n 13.105, de 16 de março de 2015. Brasília, DF: Diário Oficial da União, 2015.

BRASIL. Resolução no 125 do Conselho Nacional de Justiça, de 29 de novembro de 2010. Disponível em: https://atos.cnj.jus.br/atos/detalhar/atos-normativos?documento=156. Acesso em: 05 jul 2020. 
FERREIRA, Verônica Apparecida da Motta Cezar. Família, separação e mediação: uma visão psicojurídica. 3. ed. São Paulo: Método, 2007.

GOLDBERG, Flávio. Mediação em direito de família: aspectos jurídicos e psicológicos. Indaiatuba, São Paulo: Editora Foco, 2018.

GORETTI, Ricardo. Manual de mediação de conflitos. Rio de Janeiro: Editora Lumen Juris, 2012.

Mediação e acesso à justiça. Salvador: Editora JusPodivm, 2016.

Gestão adequada de conflitos. Salvador: Editora JusPodivm, 2019.

Mediação e acesso à justiça. 2. ed. Salvador: Editora JusPodivm, 2020. No prelo.

MAGAlHÃES, Filipa Alexandra Maia. Mediação familiar: a solução negociada dos conflitos familiares. 2014. Dissertação (Especialização em Ciências Jurídico-Forenses). Faculdade de Direito, Universidade de Coimbra, Coimbra, 2014.

MULLER, Jean-Marie. Não-violência na educação. Tradução: Tônia Van Acker. São Paulo: Palas Athena, 2006.

O princípio da não-violência. Tradução: Inês Polegato. São Paulo: Palas Athena, 2007.

NUNES, Antônio Carlos Ozório. Manual de Mediação: guia prático da autocomposição. São Paulo: Editora Revista dos Tribunais, 2016.

PARKINSON, Lisa. Mediação familiar. Tradução: Erica de Paula Salgado. 1. ed. Belo Horizonte: Del Rey, 2016.

POPPER, Karl. O mito do contexto: em defesa da ciência e da racionalidade. Lisboa: Edições 70, 2009.

RODRIGUES, Horácio Wanderlei. Acesso à justiça no direito processual brasileiro. São Paulo: Acadêmica, 1994.

SERPA, Maria de Nazareth. Mediação uma solução judiciosa para conflitos. Belo Horizonte: Del Rey, 2017.

SILVA, João Roberto da. A mediação e o processo de mediação. São Paulo: Paulistanajur, 2004.

WALTRICH, Dhieimy Quelem. A mediação comunitária como política pública democratizadora de acesso à justiça: descrição e análise do Projeto Justiça Comunitária em Passo Fundo (RS). Santa Cruz do Sul: Esse nel Mondo, 2014.

WARAT, Luis Alberto. A ciência jurídica e seus dois maridos. 2. ed. Santa Cruz do Sul: EDUNISC, 2000.

Surfando na pororoca: ofício do mediador. Florianópolis: Fundação Boiteux, 2004.

Rio de Janeiro: Editora Lumen Juris, 2010.

A Rua Grita Dionísio! Direitos Humanos da Alteridade, Surrealismo e Cartografia.

WATANABE, Kazuo. Acesso à ordem jurídica justa: conceito atualizado de acesso à justiça, processos coletivos e outros estudos. Belo Horizonte: Del Rey, 2019.

XAVIER, Beatriz Rêgo. Um novo conceito de acesso à justiça: propostas para uma melhor efetivação de direitos. Pensar-Revista de Ciências Jurídicas. v. 7, n. 1, p. 146-153, 2002. 